\title{
DIMENSIÓN ÉTICA EN LA PRÁCTICA ODONTOLÓGICA. VISIÓN PERSONALISTA
}

\author{
Roba Izzeddin Abou*, María Spina**, Egilda Tosta***
}

\begin{abstract}
Resumen: En la práctica odontológica, los profesionales enfrentan permanentemente diversos dilemas éticos. Cada odontólogo debe tomar determinaciones sobre si tiene o no competencia para realizar un diagnóstico particular o para llevar a cabo tratamientos específicos en determinadas circunstancias clínicas. Asuntos como éstos han dado lugar a un número cada vez mayor de discusiones y debates respecto de la ética en cuidados de la salud. Las preocupaciones de carácter ético resultan especialmente relevantes en el campo de la odontología, en virtud de que, a medida que crece el número de estudios en este campo, se estrecha la línea que separa la práctica de la obtención de información con fines de investigación.
\end{abstract}

Palabras clave: ética, salud, práctica odontológica

\section{ETHICAL DIMENSION IN DENTISTRY PRACTICE. PERSONALIST VIEWPOINT}

\begin{abstract}
In the practice of dentistry, professionals face diverse ethical dilemmas permanently. Every dentist must make determinations whether he/she has competence for a particular diagnose or to carry out specific treatments in specific clinical circumstances. Issues such as these have given place to increasing discussions and debates with respect to health care ethics. Ethical worries are specially relevant in dentistry field, since while number of studies increase in this field, the limit separating practice from obtaining information for research purposes is narrowed.
\end{abstract}

Key words: ethics, health, dentistry practice

\section{DIMENSÃO ÉTICA NA PRÁTICA ODONTOLÓGICA. VISÃO PERSONALISTA}

Resumo: Na prática odontológica, os profissionais enfrentam permanentemente diversos dilemas éticos. Cada odontólogo deve tomar decisões acerca de sua competência ou não para realizar um diagnóstico particular ou levar a cabo tratamentos específicos em determinadas circunstâncias clínicas. Assuntos como estes têm dado lugar a um número cada vez maior de discussóes e debates a respeito da ética em cuidados da saúde. As preocupaçóes de caráter ético resultam especialmente relevantes no campo da odontologia, em virtude de que, à medida que cresce o número de estudos neste campo, se estreita a linha que separa a prática da obtenção de informação com finalidades de investigação.

Palavras-chave: ética, saúde, prática odontológica

\footnotetext{
Docente Instructor, Departamento de Prostodoncia y Oclusión, Universidad de Carabobo, Valencia, Venezuela Correspondencia: rubaizzeddin@gmail.com

** Docente instructor, Facultad de Odontología, Universidad de Carabobo, Valencia, Venezuela

*** Docente agregado, Facultad de Odontología, Universidad de Carabobo, Valencia, Venezuela
} 


\section{Introducción}

Hoy en día, los cambios producidos en el área de la salud, en particular en la odontología, permitieron el nacimiento de un nuevo paradigma en la relación odontólogo-paciente. Los recientes lineamientos exigen al profesional informar a su paciente todo lo concerniente a su salud bucal, por ende, esta disciplina de servicio y auxilio, con amplia responsabilidad social e individual, independiente de la indiscutible efectividad técnica lograda, no se sustenta exclusivamente en la continuidad y profundización del desarrollo terapéutico y clínico; por el contrario, el odontólogo tiene una misión rehabilitadota integral con los pacientes.

Por tal motivo, diferentes países de Europa y Norteamérica han ido instalando esta temática en sus legislaciones y sistemas de salud. Tal es el caso de Holanda, donde se promulgó en 1995 una ley llamada "Acta de Contrato del Tratamiento Médico”, que establece que los pacientes tienen el derecho a recibir información y los médicos y odontólogos la obligación de informarles y pedir su autorización para los distintos procedimientos (consentimiento informado). Por otro lado, determina que los odontólogos deben comprometerse en invertir más tiempo para lograr que las decisiones sean formuladas libremente y en desarrollar los requisitos de las habilidades comunicacionales(1).

Así, la problemática mencionada surge desde las bases de la educación odontológica, en la cual los estudiantes invierten demasiado tiempo en cumplir con requisitos que pueden dificultar la relación con sus pacientes(2).

En vista de esto, países como Estados Unidos, España e Italia han generado no sólo jurisprudencia en la temática, sino también numerosos espacios de formación académica (3).

En pocas oportunidades el odontólogo se ve enfrentado a decisiones de vida o muerte, pero debe asumir y solucionar complejas cuestiones éticas. Tiene un deber de conducta con su vida profesional, en concordancia con los principios éticos(4). De igual manera, además de garantizar la confidencialidad a sus pacientes, debe presentar las distintas alternativas de tratamiento, obtener su consentimiento y respetar sus decisiones(5).

El propósito de este artículo es, en primer lugar, presentar una breve historia de la ética profesional en odontología desde el punto de vista personalista y, en segundo, analizar someramente los cuestionamientos éticos odontológicos desde una visión bioética, es decir, sobre la base de valores y principios morales. En este sentido, se trata de observar la conducta humana en el ámbito de las ciencias tanto de la vida como de la salud, procurando facilitar pautas que faciliten el análisis bioético y la toma de decisiones clínicas.

\section{Bioética en la relación clínica odontológica}

La bioética nace de la necesidad de que la ciencia biológica se plantee preguntas éticas sobre la relevancia moral de su intervención. Por ende, con la aparición de la medicina oral, a mediados del siglo XX, se inició la integración del ejercicio de la odontología con el cuerpo médico, promoviendo la formación de especialistas en todas las áreas odontológicas, lo que conllevó a su vez a su desarrollo desde el punto de vista ético.

Para Albornoz y colaboradores, la bioética es el estudio sistemático de la conducta moral en las ciencias de la vida(6). También es definida como la disciplina que estudia los aspectos éticos de la medicina y la biología, en general, así como de las relaciones del hombre con los demás seres vivos(7). Una de sus funciones es hacer conciencia entre los profesionales e investigadores de que se debe anteponer la ética a otros intereses. El criterio fundamental de la bioética es el respeto al ser humano, a sus derechos, bienestar y dignidad.

La bioética es también una rama de la ética práctica que se aboca a estudiar y a dar respuestas particulares a problemas morales que surgen en la salud, incentivando una cultura de respeto a los seres vivos humanos y no humanos, y preservando el medio ambiente para nosotros y las generaciones futuras. No obstante, propicia una toma de conciencia sobre las implicaciones morales y sus consecuencias en las áreas ya mencionadas $(8,9)$. Por ende, vale la pena resaltar los rasgos definitorios de la bioética moderna:

a) se trata de un marco interdisciplinario de reflexión ética;

b) es básicamente una ética práctica, de aplicación inmediata en el mundo de la medicina y su entorno, cuyos principales protagonistas son el médico y el paciente;

c) se trata de una reflexión ética que soporta, además, decisiones de salud pública de gran repercusión social y legal, y 
d) nadie puede permanecer ajeno a la bioética, porque ella determina una praxis sanitaria e involucra comportamientos que someten a prueba el sistema de valores que opera en una sociedad(10).

Debido a que nuestra sociedad es pluralista y compleja, necesitamos nuevas herramientas para ayudarnos en la toma de decisiones y crear conciencia bioética con enfoque integral, cuyas bases se sustenten en el código ético.

\section{Códigos de ética y asociación profesional}

Cuando se atiende a seres humanos, como sucede en la práctica odontológica, debe tenerse cuidado para asegurar que sus derechos estén protegidos. Cada profesión tiene normas, generalmente implícitas y no declaradas, sobre la correcta vinculación entre sus miembros. Desde fines de 1970, y dentro de la odontología organizada de países desarrollados, se observó un crecimiento sostenido del interés en situaciones elaboradas de la ética profesional. La experiencia indica que en décadas anteriores hubo poca voluntad para enfrentar los dilemas éticos en muchas áreas sensibles de la práctica odontológica. La causa está en la subestimación del problema en cuanto a los sucesos contemporáneos abiertos a la opinión pública. Así como en otras profesiones, las obligaciones hacia el paciente son mandatarias; sin embargo, este principio no brinda respuestas automáticas a las complejidades generadas por estas situaciones.

Los profesionales de la odontología tienen la obligación de controlar la calidad de sus prácticas, reportando y refiriendo casos de trabajos de mala calidad y prácticas no éticas. Todos entienden que los profesionales odontólogos se deben respeto mutuo, pero la mala praxis es un hecho de difícil manejo: el odontólogo que descubre esto podría informar al paciente acerca del trabajo mal realizado o bien ocultárselo. Por otra parte, puede contactarse con el profesional que realizó el trabajo o, posiblemente, con la sociedad odontológica local.

En países desarrollados, académicos, odontólogos y sus organizaciones representativas han hecho un esfuerzo conjunto para formular una base ética alcanzable, que sustente el suministro de un servicio de sanidad bucal de alta calidad. Así, y respondiendo a nuevas y significativas cuestiones generadas dentro de un clima social cambiante, la Asociación Dental Americana, luego de un considerable debate, presentó en 1992 una cantidad de revisiones y correcciones de los "Principios de Ética y Código de Conducta Profesional":

1. El personal de salud bucal debe reconocerse a sí mismo como ser humano, para posteriormente reconocer en el paciente al otro, a la persona que tiene una dignidad inalienable, poseedora de valores, que está inmersa en su medio ambiente, y no sólo como un individuo que busca y tiene necesidad de salud.

2. El personal de salud bucal debe cuidar y tratar con la misma conciencia y solicitud a todas las personas sin distinción de raza, religión, ideas políticas, condición social, nacionalidad, género, preferencia sexual o cualquier otra circunstancia personal o social.

3. El personal de salud bucal debe evitar cualquier acto que pueda denigrar el honor o la dignidad del ejercicio de la profesión, ya sea mentira, engaño, abuso, puesto que la práctica odontológica debe ser orientada bajo principios éticos, científicos y legales.

4. La calidad de la atención en los servicios de salud bucal que se otorgan a la población abierta, ya sea del sector público, privado o en instituciones educativas, debe ser la misma. No debe haber diferenciación de la atención entre una práctica institucional y la práctica en consultorio privado. Asímismo, se debe evitar el aprovecharse de la práctica institucional para llevar pacientes a la propia práctica privada.

5. El personal de salud bucal debe contar con las respectivas acreditaciones para llevar a cabo el ejercicio de su profesión, ya sea de práctica general o como especialista, y no ostentar un grado académico con el que no se cuenta.

6. El personal de la salud bucal está obligado a guardar el secreto profesional tanto del contenido de la historia clínica, así como también de todo lo que, por razón de su profesión, haya visto, escuchado y/o comprendido en relación con todos los pacientes. El secreto profesional debe reservarse aun cuando la relación profesional haya finalizado; ya sea de manera temporal o definitiva, éste se podrá revelar sólo si requiere alguna autoridad competente.

7. El personal de salud bucal debe asumir el compromiso para la educación continua y permanente en las áreas ética, científica y técnica, con el fin de 
brindar a sus pacientes el máximo de posibilidades de atención(11).

Para enriquecer lo mencionado y procurar el correcto ejercicio de la profesión, es menester que el personal dedicado a la salud bucal esté comprometido con los principios bioéticos: principio de totalidad, principio terapéutico, libertad y responsabilidad, solidaridad y subsidiariedad, beneficencia y justicia.

Bajo esta perspectiva, la profesión odontológica debe percibir el respeto a los derechos del paciente no sólo como un deber, sino como un escenario entre dos personas con necesidades diferentes que obtienen respuesta material y social en la relación terapéutica. El verdadero enfoque profesional está contenido en el encuentro humano llevado a cabo entre odontólogo y paciente; por lo tanto, es fundamental analizar la motivación que el enfermo ha tenido para ir en busca de la colaboración del profesional, en este caso de la odontología.

Se debe entender esta actividad como una profesión científica basada en los valores universales del ser humano, cuyo camino es diferenciador siempre y cuando la calidad profesional posibilita interiorizar en la afección de la persona que sufre por causa de una patología.

En consecuencia, la ética y la bioética deben ser elementos preventivos, con la posibilidad de transformar la práctica médica y odontológica influyendo en ellas como modo de vida que protege los valores sociales. Así, el diagnóstico, pronóstico y plan de tratamiento constituyen una pirámide para otorgar al paciente las óptimas condiciones de salud odontológica integral.

\section{Referencias}

1. Espinosa A. Análisis de expedientes de quejas del área de odontología. Rev de la CONAMED 2000; 4; 6(17): 5-7.

2. Van Dam S. Requirement-driven dental education and the patient's right to informed consent. J Am Coll Dent 2001; 68(3): 40-47.

3. Nash DA. Ethics in dentistry: review and critique of Principles of Ethics and Code of Professional Conduct. J Am Assoc 1984; 109(4): 597-603.

4. Lolas F. Bioética y antropología médica. Santiago de Chile: Editorial Mediterráneo; 2000.

5. Francisconi C. Sida y bioética. Rev Topodrilo 1998; 50(6): 21-24.

6. Albornoz C, Machado C, Agüero A, Cabrera V. Aspectos éticos de la investigación clínica en seres humanos. Revista de Humamidades Médicas 2003; 3(2).

7. Carrera JM. Bioética como nueva disciplina, historia y actualidad. Buenos Aires: Universidad de Buenos Aires (Facultad de Medicina); 2007. Disponible en: http://www.monografias.com/trabajos16/nueva-bioetica/nueva-bioetica.shtml

8. Nash DA. Ethics in dentistry: review and critique of Principles of Ethics and Code of Professional Conduct. J Am Assoc 1984; 109(4): 597-603.

9. Secchi MA. Aspectos diversos de responsabilidad Rev Soc Argent Ped 1999; 15(2): 77-81.

10. Escríbar A. Raíces de la bioética en la tradición ético-filosófica occidental y actuales desafíos. An Univers Chile 1998; Sexta Serie (8).

11. American Dental Association. Council on Ethics, Bylaws and Judicial Affairs. Principles of Ethics and Code of Professional Conduct. With official advisory opinions revised to January 2010.

Recibido: 27 de agosto de 2009

Aceptado: 15 de octubre de 2009 